\title{
Paulo Freire e sua influência \\ na pedagogia crítica nos Estados Unidos
}

\author{
Paulo Freire and his influence \\ on the critical pedagogy in the United States
}

Paulo Freire y su influencia

en pedagogía crítica en los Estados Unidos

\section{IVANILDE APOLUCENO DE OLIVEIRA*}

Universidade do Estado do Pará, Belém- PA, Brasil.

MARIA INÊS MARCONDES ${ }^{* *}$

Universidade Católica do Rio de Janeiro, Rio de Janeiro- RJ, Brasil.

TANIA REGINA LOBATO DOS SANTOS ${ }^{* * *}$

Universidade do Estado do Pará, Belém- PA, Brasil.

\begin{abstract}
RESUMO: Os objetivos deste artigo são analisar como se deu a influência da pedagogia crítica de Paulo Freire nos Estados Unidos; em que consiste a pedagogia crítica de Paulo Freire; quais as fontes de seu pensamento; quais as principais categorias. Essas são as questões principais que este artigo procura responder. $\mathrm{O}$ texto tem por base a pesquisa bibliográfica. Destaca-se que Paulo Freire é reconhecido como uma das principais referências da pedagogia crítica nos Estados Unidos.

Palavras-chave: Pedagogia crítica. Paulo Freire. Estados Unidos.
\end{abstract}

* É doutora em Educação pela Pontifícia Universidade Católica de São Paulo e, atualmente, professora da Universidade do Estado do Pará, instituição na qual coordena o Núcleo de Educação Popular Paulo Freire. E-mail:<nildeapoluceno@uol.com.br>.

** É doutora em Educação pela Pontifícia Universidade Católica do Rio de Janeiro, mesma instituição na qual atua como professora. Atualmente é membro do Comitê Editorial da Revista Teachers and Teaching (UK- Taylor and Francis Group). E-mail: <mim@puc-rio.br>.

*** É doutora em Educação pela Pontifícia Universidade Católica de São Paulo. Atualmente é professora da Universidade do Estado do Pará e coordena o Grupo de Pesquisa Infância Cultura e Educação e pesquisadora do Núcleo de Educação Popular Paulo Freire. E-mail: <tania02lobato@gmail.com>. 


\begin{abstract}
The objectives of this article are to analyze how the influence of Paulo Freire's critical pedadogy took place in the United States: what Paulo Freire's critical pedagogy consists of; what are the sources of his thinking; and which are the main categories. These are the main questions this article is meant to answer. The text has bibliographical research as its basis. Paulo Freire stands out as one of the main references in critical pedagogy in the United States.
\end{abstract}

Keywords: Critical pegadogy. Paulo Freire. The United States.

RESUMEN: Los objetivos de este artículo son analizar cómo se produjo la influencia de la pedagogía crítica de Paulo Freire en los Estados Unidos; en qué consiste la pedagogía crítica de Paulo Freire; cuáles son las fuentes de su pensamiento; cuáles son las categorías principales. Estas son las principales preguntas a las que este artículo busca dar respuesta. El texto se basa en una investigación bibliográfica. Es de destacar que Paulo Freire es reconocido como uno de los principales referentes de la pedagogía crítica en Estados Unidos.

Palabras clave: Pedagogía crítica. Paulo Freire. Estados Unidos.

\title{
Introdução
}

P aulo Freire tem sido mencionado por diversos autores, entre os quais Giroux e McLaren como principal referencial da pedagogia crítica nos Estados Unidos.

A pedagogia crítica de Paulo Freire, conforme Oliveira (2005) evidencia o caráter político e dialético de seu pensamento educacional, bem como a sua fundamentação Marxista quanto personalista. Essa combinação de diferentes referenciais teóricos pode ser vista como um ponto forte no seu pensamento ou como uma fraqueza por alguns críticos de sua obra. Gadotti (1993) considera que a educação freireana relaciona dialeticamente a educação com os determinantes sociais, políticos e culturais da sociedade.

Assim, Paulo Freire se contrapõe à pedagogia tradicional, não crítica e não histórica e anuncia uma pedagogia crítica, dialética, política e historicamente construída.

O autor problematiza o discurso fatalista neoliberal e, partindo das contradições sociais e das relações de poder existentes, anuncia uma pedagogia crítica e democrática, com perspectivas históricas de transformação social. Com isso, o seu pensamento educacional se amplia como teoria crítica, sendo analisada nos diferentes níveis e modalidades de ensino, deixando ser foco apenas da educação de jovens e adultos e da educação popular. 
Torres (2001) destaca que a pedagogia crítica educacional de Paulo Freire se inicia no Brasil e circula na América Latina, Estados Unidos, Canadá e África. Na mesma direção, Jara (2009) destaca que a filosofia da Freire não se restringiu à América Latina de onde tem sua origem, mas circulou por diversos países e continentes.

\begin{abstract}
[...] Essa filosofia em construção está presente desde os seus primeiros escritos, marcados pela intensa experiência no Brasil dos anos cinquenta e sessenta, e foi enriquecendo-se ao longo do seu exílio, sempre recriando seu pensamento diante de cada novo desafio: primeiro na Bolívia, depois no Chile, onde esteve de 1964 a 1969, posteriormente nos Estados Unidos, e depois trabalhando com o Conselho Mundial das Igrejas em Genebra de 1970 a 1980, parte de cujo tempo passou vinculado à experiência educativa de Guiné Bissau, até voltar novamente à América Latina, especialmente no seu último período de compromisso político, pedagógico e pessoal no Brasil (JARA, 2009: 38).
\end{abstract}

Para Giroux (1998:194), Paulo Freire é uma referência no pensamento crítico e na "pedagogia dialógica em diversas partes do mundo", sendo forte sua presença na América do Norte. Considera Freire um "intelectual de fronteira", pois se encontra em diferentes fronteiras culturais, epistemólogicas e espaciais, sendo um "atravessador de fronteiras". Desta forma, há a influência da pedagogia crítica Freireana em contextos diferenciados entre os quais a America Latina e os Estados Unidos.

Mas, como se deu essa influência da pedagogia crítica de Paulo Freire nos Estados Unidos? Em que consiste a pedagogia crítica de Paulo Freire? Quais as fontes de seu pensamento? Quais as principais categorias? Essas são as questões principais que este artigo procura responder.

O texto tem por base a pesquisa bibliográfica, como fontes primárias escritos do próprio Paulo Freire e de autores que escreveram sobre a educação de Paulo Freire.

Assim, apresentamos a influência da pedagogia crítica de Paulo Freire no contexto norte-americano e, em seguida, como se caracteriza, seus principais pressupostos e categorias.

\title{
A influência da pedagogia crítica nos Estados Unidos
}

Na condição de exilado político na década de 1960, Freire publica o livro “Pedagogia do Oprimido" nos Estados Unidos, em 1970, em língua inglesa, antes de ser publicado no Brasil e, até 1974, o livro tinha sido traduzido para o espanhol, italiano, francês, alemão, holandês e sueco, e, em consequência, foi amplamente lido por educadores de várias partes do mundo. Muitos desses educadores buscavam uma alternativa para o paradigma tradicional de ensino, que, na área dos estudos curriculares, tinham finalidades específicas de organização do trabalho pedagógico nas escolas, sem questionar qual conhecimento era ensinado, como era ensinado e por que era ensinado. Esses educadores encontraram na obra de Freire subsídios para fundamentar a construção de um novo 
paradigma - uma pedagogia crítica. Especificamente nesta obra, Freire incorpora experiências de estudo e de seu trabalho de campo no Brasil, especificamente no Nordeste, e no Chile, com trabalhadores rurais e sindicalistas. Além de suas leituras com o grupo de intelectuais e jovens colaboradores que desenvolviam com ele a experiência no Instituto de Capacitación e Investigación em Reforma Agrária (Icira), órgão misto das Nações Unidas e do Governo do Chile. Ele deixa claro que o livro é resultado de suas leituras e experiências práticas nesses diferentes contextos de intervenção, estudo e pesquisa. (MARCONDES, 2018a).

$\mathrm{Na}$ Pedagogia do Oprimido, desenvolve crítica à educação tradicional, denominada de “educação bancária' e elabora uma proposta de educação problematizadora, que teria como base o diálogo e uma relação horizontal entre educador e educando, tornando o trabalho, na época, extremamente original, de caráter inovador e que poderia contribuir para um enfoque mais crítico da escola e do processo de ensino-aprendizagem como um todo. O conteúdo de ensino, a forma de desenvolver esse processo e as finalidades últimas da educação eram discutidas amplamente no livroe o olhar para os oprimidos tornaram os seus escritos uma leitura indispensável para todos que buscavam uma pedagogia crítica e engajada, usando o termo da época, libertação, pedagogia como prática da liberdade.

Nos Estados Unidos, Paulo Freire não foi visto apenas como um educador de adultos, mas fonte importante e destacada do movimento da pedagogia crítica, tendo como referências educadores como Henry Giroux, Peter McLaren, entre outros. O próprio Paulo Freire (1998:xiii) afirma:

[...] nos últimos anos, educadores como Henry Giroux, Peter McLaren, Ira Shor, Carlos Alberto Torres, Donaldo Macedo e Bell Hooks, entre outros, tentaram reiventar meus trabalhos e pesquisas sobre alfabetização e pedagogia para que pudessem ser aplicados às lutas norte-americanas pela libertação nas escolas, no local de trabalho, em casa, nas universidades e faculdades.

Assim, o próprio Freire ressalta que sua proposta teria como base processos e pesquisas em alfabetização de adultos no Brasil e no Chile, tanto no aspecto de um trabalho prático como nas reflexões teóricas que desenvolve na Pedagogia do Oprimido, e que trazem contribuições importantes para todos que buscavam ver a educação nas escolas com o papel de transformação de uma sociedade mais justa e igualitária.

McLaren (1999) considera Paulo Freire o filósofo inaugural da pedagogia crítica e chama atenção ao fato dele ter efetivado uma reorientação global da pedagogia, direcionando-a à política da libertação, significativa para os movimentos ativistas no mundo. Explica que "Freire foi sempre fundamental para o desenvolvimento de minha pedagogia crítica" (McLAREN, 2007: 01). Assim, MacLaren reconhece Paulo Freire como gênese 
da pedagogia crítica nos Estados Unidos, afirmando a influência freireana no seu pensamento educacional.

Giroux (1998:191) expressa sobre a tendência freireana nos Estados Unidos que, em alguns lugares, o nome de Paulo Freire "[...] tornou-se sinônimo do próprio conceito e prática de pedagogia crítica. Progressivamente o trabalho de Freire tem-se tornado a referência padrão para engajar no que é muitas vezes referido como ensino para o pensamento crítico, pedagogia dialógica ou alfabetização crítica". Em sua obra "Os professores como intelectuais transformadores" Giroux incorpora no conceito de professor como intelectual transformador princípios de Freire e Gramsci.

A pedagogia de Paulo Freire, então, se apresenta nos Estados Unidos como crítica e dialógica, sendo focada no ensino.

MacLaren (1999) e Giroux (1998) tratam a pedagogia crítica de Paulo Freire na perspectiva filosófica, tendo uma base teórica. Por outro lado, Aronowitz (1998:103) explica que em algumas vezes ela era interpretada nos Estados Unidos como "brilhante metodologia de um caráter extraordinário e politicamente provocativo". Esta é uma das críticas que se faz a uma apropriação indevida da proposta freireana.

Na década de 1980, Paulo Freire publica com Ira Shor o seu primeiro livro dialogado Medo e Ousadia. Neste livro retoma alguns equívocos da interpretação de sua obra, assim como novos desdobramentos de suas reflexões com o passar dos anos.

Marcondes (2018b) faz uma análise desses aspectos, destacando que Freire e Shor buscavam naquele momento, basicamente, responder às dúvidas dos professores americanos sobre a possibilidade de aplicação no "Primeiro Mundo" de uma pedagogia gestada no “Terceiro Mundo". Essas terminologias, "Primeiro Mundo" e “Terceiro Mundo", amplamente utilizadas no diálogo entre os dois, eram muito usadas na época, tendo hoje caído em desuso e não sendo mais utilizadas por terem adquirido uma conotação negativa.

A autora ressalta que há uma nítida preocupação no livro em reafirmar posições, clarificar conceitos, assim como desfazer equívocos e propor alternativas de aplicação de propostas conceituais apresentadas nas obras anteriores. A proposta de uma educação dialógica, em alguns meios educacionais, ficou identificada como uma pedagogia nãodiretiva e sem rigor acadêmico. Freire retoma, com veemência, a concepção de diálogo, reafirmando que não se trata de uma técnica descolada de uma concepção de educação emancipadora, libertadora ou liberadora.

[...] Antes de mais nada, Ira, penso que deveríamos entender o diálogo não como uma técnica apenas que podemos usar para conseguir obter alguns resultados. Também não podemos, não devemos, entender o diálogo como uma táctica que usamos para fazer dos alunos nossos amigos. Isso faria do diálogo uma técnica para a manipulação, em vez de iluminação. Ao contrário, o diálogo deve ser entendido como algo que faz parte da própria natureza histórica dos seres humanos. É parte de nosso progresso histórico do caminho para nos tornarmos seres humanos. [...] O diálogo é o momento em que os humanos se encontram para refletir sobre sua realidade tal como o fazem e re-fazem (FREIRE; SHOR, 1986:122). 
O diálogo, como técnica de ensino, foi apropriado por diferentes autores nos Estados Unidos e desvinculado dos princípios mais teóricos da proposta freireana. Porém, o diálogo em Freire apresenta, além da dimensão metodológica, aspectos ontológicos, ao considerá-lo inerente ao existir humano e epistemológico, na perspectiva de conhecimento e de comunicação entre os sujeitos.

A questão da autoridade foi, também, em muitos casos, tratada sem o devido rigor que Freire deu em sua proposta. O autor critica o autoritarismo e não nega a autoridade e diretividade do docente no processo educativo. Assim, um dos aspectos reafirmado no livro é que há autoridade na figura do professor, mas que os conceitos de autoridade e autoritarismo são diferentes. $\mathrm{O}$ autor compreende que a educação dialógica não se identifica com práticas espontaneístas, não diretivas e pouco rigorosas. Defende uma ação planejada com objetivos definidos, uma proposta política com metas claras e delineadas, buscando empoderar alunos, valorizando sua experiência e reconhecendo seu conhecimento como válido.

[...] através dessa forma de entender o diálogo, o objeto a ser conhecido não é de posse exclusiva de um dos sujeitos que fazem o conhecimento, de uma das pessoas envolvidas no diálogo.[...] O contato prévio do educador com o objeto a ser conhecido não significa, no entanto, que o professor tenha esgotado todos os esforços e todas as dimensões no conhecimento do objeto. (FREIRE; SHOR, 1986:123)

[...] A educação dialógica é uma posição epistemológica e não uma invenção bizarra ou uma prática estranha vinda de uma parte exótica do mundo! [...] Precisamente porque há uma epistemologia aqui, minha posição não é a de negar o papel diretivo e necessário do educador. Mas não sou o educador que se considera dono dos objetos que estudo com os alunos. Estou extremamente interessado nos objetos de estudo eles estimulam minha curiosidade e trago essas entusiasmo para os alunos. Então podemos juntos iluminar o objeto (FREIRE; SHOR, 1986:125).

Os autores, então, reafirmam a importância de esclarecer que a educação dialógica pode ser aplicada em diferentes contextos, visando tornar sociedades com mais justiça social e igualdade. Freire, nesta obra, também se preocupa em constatar os limites de uma educação transformadora.

Desta forma, transcorridos mais de dez anos da publicação da Pedagogia do Oprimido (1970), Freire reconhece limites de sua proposta e da ideia que a educação tinha grande poder na transformação das injustiças da sociedade. Reconhece que seus escritos podem ter ajudado a reforçar essa ideia e a questão é retomada em outras bases. "[...] Sei que o ensino não é a alavanca para a mudança ou a transformação da sociedade, mas sei que a transformação social é feita de muitas tarefas pequenas e grandes, grandiosas e humildes!" (FREIRE; SHOR, 1986:60).

Ele nos lembra (FREIRE; SHOR, 1986:64) que nenhuma tarefa deve ser considerada menor. Tudo deve ser visto como parte de um processo mais amplo. “[...] Devemos evitar o pensamento de que nós somos os iluminadores. Creio que a educação libertadora 
implica a iluminação da realidade, mas os iluminadores são os dois agentes do processo, os educadores e os educandos juntos". Tanto o educador como o educando têm sua parte no processo de desenvolver uma educação crítica. Mesmo reconhecendo que a realidade não pode ser transformada apenas pela ação educacional, Freire, nos anos 1980, apresenta uma visão mais realista, que incorpora as críticas ao seu trabalho.

\begin{abstract}
[...] Precisamente porque a educação não é a alavanca para a transformação da sociedade, corremos o perigo do desespero e do ceticismo, se limitarmos nossa luta à sala de aula. [...] Devemos saber que é possível conseguir algumas coisas importantes no espaço institucional de uma escola, ou faculdade, para ajudar a transformação da sociedade. Se compreendermos a natureza limitada e vinculada de educação, se compreendermos como a educação formal se relaciona com a sociedade global, sem ser, apenas, a reprodutora da ideologia dominante, e sem ser, também, a principal alavanca da transformação (FREIRE; SHOR, 1986:157).
\end{abstract}

Freire (FREIRE; SHOR, 1986:158) reconhece os limites, mas reafirma a importância do trabalho político dentro e fora das salas de aula. "[...] Conhecer os limites da educação não me levou a reduzir minha atividade nessa área, mas, pelo contrário, ampliou meus objetivos políticos. Mas, sobretudo, ampliei meu trabalho político fora das escolas".

Ao final do livro, Shor traz para a discussão com Freire as temáticas do racismo e do sexismo, explicando que essas duas dimensões são inevitáveis na vida social e na educação. Shor defende a inclusão dessas discussões na sala de aula dialógica que deve ser objeto de estudo crítico. Freire (FREIRE; SHOR, 1986:199) afirma que: [...] "se realmente queremos reinventar a sociedade, para que as pessoas sejam cada vez mais livres, e mais criativas, esta nova sociedade que deve ser criada por homens e mulheres não pode ser racista, não pode ser sexista". Conclui destacando que devemos educar as pessoas para serem livres, para podermos transformar a realidade simultaneamente; por isso, devemos estar engajados na ação política contra o racismo e contra o sexismo.

Assim, Freire se coloca como um "intelectual de fronteira", de acordo com Giroux (1998). Isto significa que amplia a sua teoria crítica, ao envolver o debate de questões referentes às diferenças e às diversidades culturais.

No prefácio da publicação da 30ª edição da Pedagogia do Oprimido em língua inglesa, publicada nos Estados Unidos, em 2000, Donaldo Macedo explica que muitos transformaram a pedagogia dialógica em um método de ensino, deixando de fora a concepção mais ampla e crítica do processo educacional de Freire. A metodologia proposta só tem sentido se tem como pano de fundo a ideia da educação que possibilita modificações, tornando a sociedade mais justa e igualitária.

Mesmo tendo reconhecido que a educação, sozinha, não tem o poder de transformar a sociedade e que seu potencial emancipador tem limites bem traçados, Freire continuou a defender que a luta dos educadores não se limita ao espaço escolar, envolve a luta em diversos âmbitos fora da escola. A educação escolar é um dos espaços, mas não é o único 
responsável pela transformação da sociedade. Os limites de sua própria proposta de emancipação são reconhecidos por ele na década 1980.

Desta forma, seja como pensamento ou como método, Paulo Freire vem influenciando, conforme Oliveira e Bezerra (2018), o pensamento crítico nos Estados Unidos e uma de suas principais obras continua sendo a Pedagogia do Oprimido.

[...] As suas publicações são amplamente difundidas como bases norteadoras de muitas pequisas sobre mudança e justiça social, e pedagogia crítica e inovadora. Algumas universidades mantém projetos como o Teatro do Oprimido, comunidades de pesquisa de campo que incluem metodologia de ensino e aprendizagem proposta por Freire, acervos de suas obras, eventos acadêmicos, jornais "online" com resenhas e outros artigos publicados sobre seu trabalho e formas de pensar, e até mesmo disciplinas de graduação e mestrado para professores da área de educação que incluem abrangentes conteúdos acerca das temáticas trabalhadas por Freire (OLIVEIRA; BEZERRA, 2018:119).

Logo, Paulo Freire contribuiu e contribui, ainda, para o pensamento e a educação crítica nos Estados Unidos.

\section{A educação crítica de Paulo Freire: pressupostos e principais categorias}

A educação crítica de Paulo Freire tem por base as seguintes categorias: a criticidade, a conscientização, a libertação, a problematização, a pergunta e a esperança.

\section{A criticidade, a conscientização e a libertação}

Freire incorpora em várias fases de seu trabalho diferentes referenciais teóricos em suas reflexões. Na educação crítica, Paulo Freire apresenta pressupostos teóricos de Marx e Gramsci, como também a influência dos pós-marxistas, teóricos da Teoria Crítica da Escola de Frankfurt, entre os quais Erich Fromm e Herbert Marcuse.

Freire aproxima-se de Marx e Gramsci ao trabalhar a educação como ato político e elaborar uma proposta dialética de educação, engajada politicamente com as classes populares e grupos sociais oprimidos, analisando criticamente o processo de autoritarismo e de alienação no discurso educacional no sistema capitalista.

Oliveira (2015) explica que Paulo Freire utiliza no desenvolvimento de seu pensamento educacional conceitos marxistas, entre os quais: classe, práxis, alienação e libertação. Essa influência marxista se deu durante seu período de exílio no Chile, quando teve contato mais direto com essas leituras.

Freire recebe contribuições teóricas de Gramsci ao analisar a educação como processo de conscientização crítica, sendo o sujeito capaz de compreender a razão de ser dos fatos, superando a apreensão ingênua da realidade social. A criticidade está presente no 
pensamento filosófico de Gramsci, (1991:12-13) por meio da consciência de historicidade. No ensino de filosofia destaca que este não está dedicado a

[...] informar historicamente o discente sobre o desenvolvimento da filosofia passada, mas para formá-lo culturalmente, para ajudá-lo a elaborar criticamente o próprio pensamento e assim participar de uma comunidade ideológica e cultural, é necessário partir do que o discente já conhece, da sua experiência filosófica (após tê-lo demonstrado que ele tem uma tal experiência, que ele é um "filósofo" sem o saber) (GRAMSCI, 1991:148).

Assim, na visão de Gramsci, uma ação política requer o pensar crítico e a conscientização do ser humano sobre o processo de massificação que sofre na sociedade. Por isso, conforme Oliveira (2015), ele enfatiza a importância da reflexão sobre o que acontece no contexto social, para superar a concepção fragmentária da realidade, com vista a uma concepção unitária e coerente de mundo.

Paulo Freire apropria-se de Erich Fromm na compreensão do sadismo como característica da consciência opressora, em uma perspectiva necrófila de mundo. O sadismo consiste

[...] el placer del dominio completo sobre otra persona (o sobre otra creatura animada), es la esencia misma del impulso sádico. Otra manera de formular la misma Idea es decir que el fin del sadismo es convertir um hombre em cosa, algo animado em algo inanimado, ya que mediante el control completo y absoluto el vivir pierde una cualidad esencial de la vida: la liberdad [...] Ama el control y em el acto de controlar, mata la vida (FROMM, 1967 apud FREIRE, 1983: 50 e 74).

De Herbert Marcuse Freire (1983:50) destaca o uso da ciência e da tecnologia pelas classes dominantes como "força indiscutível de manutenção da 'ordem' opressora, com a qual manipulam e esmagam".

Desta forma, Fromm e Marcuse ajudam Freire a fundamentar e debater o processo de manipulação ideológica no sistema capitalista, denunciando o sadismo e as práticas educacionais de alienação na educação tradicional, que denomina de necrófila, por se constituir em ações de desumanização.

A educação em Freire, então, dimensiona-se pela leitura crítica do mundo e da palavra, o que pressupõe o desvelar dos discursos ideológicos de interesse da classe dominante. Constitui-se em um ato de "'conscientização crítica', de desmitologização" em que se desoculta a ideologia da classe dominante. A conscientização implica que "[...] ultrapassemos a esfera espontânea de apreensão da realidade, para chegarmos a uma esfera crítica, na qual a realidade se dá como objeto cognoscível e na qual o homem [e a mulher] assume uma posição epistemológica" (FREIRE, 1980b:26).

Freire (2003) enfatiza que uma sociedade democrática visa superar as injustiças sociais, a exclusão social, a visão fatalista, o imobilismo, a acomodação dos oprimidos, a realidade injusta e dominadora. Desta forma, defende a possibilidade de construção de 
uma realidade inclusiva, que almeje a transformação social na perspectiva de uma concepção dialética de ser humano, de história e de sociedade.

A consciência crítica, na visão do autor, torna-se um processo "libertador", pois integrando-se e exercitando a práxis os homens e as mulheres se descobrem como pessoas e, deste modo, o mundo, os seres humanos, a cultura e o trabalho assumem o seu verdadeiro significado. A conscientização para Freire (1980b:26) não pode existir fora da "práxis", ou melhor, "sem o ato ação-reflexão", e o trabalho educativo humanizante libertador consiste no trabalho de desmistificação da ideologia que oculta a verdadeira realidade (FREIRE, 1983).

A educação torna-se, assim, instrumento de desalienação e de libertação, uma pedagogia do oprimido, porque estes passam a refletir sobre a sua condição de explorado e conscientes dessa situação opressora se engajam em uma luta para a libertação, visando eliminar as contradições existentes entre opressores e oprimidos cuja relação é de "poder", fundamentada nas diferenças de classes sociais, de etnias, gênero, entre outras.

Oliveira (2003) considera que a conquista da liberdade pelos oprimidos implica a construção de uma nova sociedade e o estabelecimento de uma outra relação humana, que seja solidária e dialógica. A libertação, na pedagogia crítica freireana, significa ação de libertação e conscientização dos oprimidos. A educação freireana tem um caráter libertador, pois pressupõe a libertação do ser humano enquanto sujeito, "[...] sendo capaz de problematizar e teorizar sobre a realidade social vivida e de posicionar-se criticamente perante as contradições e classe social, integrando-se a sociedade" (OLIVEIRA, 2003:28).

Ao trabalhar dialeticamente a questão política da educação e considerá-la um processo de conscientização crítica, Paulo Freire enfatiza o conceito de criticidade, que está relacionado aos conceitos de problematização e do ato de perguntar.

\section{Problematização, o ato de perguntar e a esperança}

Problematizar, em Freire (1983:198), consiste em “[...] exercer uma análise crítica sobre a realidade problema". É responder aos desafios da realidade problematizada, na condição de sujeito, visando transformá-la. Para problematizar há necessidade de questionar, de perguntar, procurando desvelar a razão de ser dos fatos.

O autor explica que o ato de perguntar não pode ser um jogo intelectualista, sendo necessário que "[...] o educando ao perguntar sobre um fato, tenha na resposta uma explicação do fato e não a descrição pura das palavras ligadas ao fato. É preciso que o educando vá descobrindo a relação dinâmica, forte, viva, entre palavra e ação, entre palavra-ação-reflexão" (FREIRE, 1985:49).

Freire (1985,1980a) propõe a pedagogia da pergunta, cuja tarefa do professor é problematizar aos educandos o mundo que os mediatiza, é estimular a curiosidade e o ato 
de perguntar no processo educativo, considerando que no ato de problematizar os educandos o educador se encontra igualmente problematizado. Ao contrário da pedagogia da pergunta, na pedagogia da resposta o professor já traz as respostas prontas para os alunos, uma prática pedagógica que limita a criatividade, a curiosidade e impossibilita a construção do conhecimento como um processo permanente.

Faundez (FREIRE; FAUNDEZ,1985: 52), em diálogo com Freire, destaca que a “[...] educação de perguntas é a única educação críativa e apta a estimular a capacidade humana de assombrar-se, de responder ao seu assombro e resolver seus verdadeiros problemas essenciais. E o próprio conhecimento".

Freire (1993) analisa a criticidade como uma questão ética. O direito à crítica não permite a mentira e requer conhecer com profundidade o objeto da crítica.

McLaren e Silva (1998:55) consideram a pedagogia crítica de Paulo Freire um fórum “[...] para construir uma nova narrativa de esperança através do desenvolvimento de uma pedagogia capaz de unir aqueles dos quais a subordinação racial, de gênero e de classe parece ter excluído a possibilidade de uma luta ativa para a subjetividade emancipada".

Assim, a criticidade em Freire (2000:42-43 e 1980b:28) está relacionada não apenas ao processo de problematização da realidade, apresenta-se, também, como perspectiva de esperança, ao considerar que "[...] a denúncia e o anúncio criticamente feitos no processo de leitura de mundo dão origem ao sonho porque lutamos". "[...] A utopia exige o conhecimento crítico".

Nesta perspectiva, o sonho político de mudança social tem por base o conhecimento crítico da realidade social.

\section{Considerações finais}

Paulo Freire em sua obra e, especialmente, no livro Pedagogia do Oprimido pode ser considerado uma das principais referências dos intelectuais na década de 1970, incluindo os Estados Unidos, que buscavam construir uma proposta educacional crítica, transformadora e emancipadora.

Porém essa influência nos Estados Unidos, em alguns momentos, ficou reduzida ao ensino e a aspectos metodológicos de sua pedagogia, não sendo tratada como uma teoria crítica, por não serem enfatizados aspectos ontológicos e nem epistemológicos. Mas esse fato não compromete a relevância de sua obra nos Estados Unidos, pelo seu reconhecimento como mentor da pedagogia crítica por autores como Peter McLaren, assim como pelo seu reconhecimento como "intelectual de fronteira", o que anuncia a abertura do pensamento de Paulo Freire ao mundo.

Alguns conceitos de sua obra foram redimensionados nos tempos atuais, porém as bases estruturais de seu pensamento educacional permanecem construídos em torno de 
algumas categorias como a criticidade, a conscientização, a libertação, a problematização, o perguntar e a esperança. Categorias fundantes que se entrelaçam e dão um suporte orgânico à sua pedagogia crítica.

A filosofia de Freire não se restringiu à América Latina de onde tem sua origem, ela circulou por diversos países e continentes. Nos Estados Unidos, os principais autores são Peter Mclaren, Catherine Walsh, Torres, Giroux, entre outros.

Paulo Freire defende a construção de uma realidade inclusiva, que almeje a transformação social na perspectiva de uma concepção dialética de ser humano de história e de sociedade. Aprendeu e ensinou, influenciou, por meio de seu pensamento educacional, intelectuais e educadores dos países em que viveu, mas aprendeu e incorporou em seu discurso pedagógico as experiências vividas e manteve a coerência teórica e metodológica dos pressupostos de sua pedagogia crítica.

Assim, apesar dos limites da educação, que foram também amplamente delineados por Freire, sua pedagogia crítica, especialmente na Pedagogia do Oprimido, continua a ser referência para os educadores críticos e pós-críticos tanto nos Estados Unidos como no mundo.

Recebido em 02/06/2020. Aprovado em 28/06/2020.

\section{Referências}

ARONOWITZ, Stanley. O humanismo radical e democrático de Paulo Freire, In: MCLAREN, Peter; LEONARD, Peter; GADOTTI, Moacir (Orgs.). Paulo Freire: poder, desejo e memórias da libertação.

Porto Alegre: ArtMed, 1998.

FREIRE, Paulo; HORTON, Myles. O caminho se faz caminhando: conversas sobre educação e mudança social. 2 ed. Petrópolis: Vozes, 2003.

Pedagogia da Indignação: cartas pedagógicas e outros escritos. São Paulo: UNESP, 2000.

Prefácio da edição em Língua Inglesa de Paulo Freire: A critical Encounter. In: MCLAREN, Peter; LEONARD, Peter; GADOTTI, Moacir (organizadores). Paulo Freire: poder, desejo e memórias da libertação. Porto Alegre: ArtMed, 1998.

Política e Educação. São Paulo: Questões da nossa época; Cortez, 1993.

FREIRE, Paulo e SHOR, Ira. Medo e Ousadia: o cotidiano do professor. Rio de Janeiro: Paz e Terra, 1986. ; FAUNDEZ, Antonio. Por uma pedagogia da pergunta. Rio de Janeiro: Paz e Terra, 1985.

. Pedagogia do Oprimido. 12 ed. Rio de Janeiro: Paz e Terra, 1983.

Extensão ou comunicação? 4 ed. Rio de Janeiro: Paz e Terra,1980a. 
Conscientização: teoria e prática da libertação - uma introdução ao pensamento de Paulo Freire. 4 ed. São Paulo: Moraes, 1980b.

Pedagogia do Oprimido. Rio de Janeiro: Paz e Terra, 1970.

GADOTTI, Moacir. História das Ideias Pedagógicas. São Paulo: Ática, 1993.

GIROUX, Henry. Paulo Freire e a política de pós-colonialismo. In: MCLAREN, Peter; LEONARD, Peter; GADOTTI, Moacir (Orgs). Paulo Freire: poder, desejo e memórias da libertação. Porto Alegre: ArtMed, 1998.

GRAMSCI, Antonio. Concepção dialética da história. 9 ed. Rio de Janeiro: Civilização Brasileira, 1991.

JARA, Oscar. Paulo Freire, filósofo de la transformación de la historia. La Piragua: Revista Latinoamericana de educación y política, Panamá: CEAAL, n. 28, 2009.

MCLAREN, Peter. Paulo Freire é o mais importante educador crítico lido nos EUA. Revista do Instituto Humanitas Unisinos, On-line. n. 223, ano VII, p.33-37, junho de 2007.

MCLAREN, Peter. Utopias provisórias: as pedagogias críticas num cenário pós-colonial.Petrópolis: Vozes, 1999.

; SILVA, Tomaz Tadeu da. Descentralizando a pedagogia: alfabetização crítica, resistência e política da memória. In: MCLAREN, Peter; LEONARD, Peter; GADOTTI, Moacir (organizadores). Paulo Freire: poder, desejo e memórias da libertação. Porto Alegre: ArtMed, 1998.

MARCONDES, Maria Inês. Freire como autor internacional: Pedagogia do Oprimido em língua inglesa publicada 50 anos atrás. Revista E-Curriculum, São Paulo, v. 16, n. 4, p. 962-985, out/dez, 2018 a.

MARCONDES, Maria Inês. Freire, da cena nacional para a internacional: diálogos sobre currículo e didática com Ira Shor. In CANDAU, Vera (Org.). Didática: tecendo/reinventando saberes e práticas. $1^{\text {a }}$ ed., Rio de Janeiro: Editora 7 Letras, 2018b.

OLIVEIRA, Ivanilde Apoluceno de; BEZERRA, Giselle Cristiane P. M. [Re]construção do pensamento crítico. In: OLIVEIRA, Ivanilde Apoluceno de; SANTOS, Tânia Regina Lobato dos; MARCONDES, Maria Inês (Orgs.) A educação de Paulo Freire nos contextos latino e norte-americanos. Belém: UEPA-CCSE, 2018.

Paulo Freire: gênese da educação intercultural no Brasil. Cutiriba: CRV, 2015.

Filosofia da Educação: reflexões e debates. Petrópolis: Vozes, 2005.

Leituras freireanas sobre educação. Série Paulo Freire/org. Ana Maria Araújo Freire. São Paulo: UNESP, 2003.

Torres, Carlos Alberto. Grandezas y miseiras de la educación latinoamericana del siglo veinte.

(Org). Paulo Freire y la agenda de la educación latinoamericana em el siglo XXI. Buenos Aires: CLACSO - Consejo Latinoamericano de Ciencias Sociales, 2001. 